\title{
FORMULASI DAN MANFAAT KRIM MINYAK JAHE MERAH DAN MINYAK CENGKEH TERHADAP NYERI HAID
}

\author{
Fitriani Annisa Al Mansur ${ }^{1 *}$, Joshita Djajadisastra ${ }^{2}$, Endang Hanani $^{2}$
}

1. Program Studi Magister Herbal Fakultas Farmasi Universitas Indonesia, Depok 16424, Indonesia

2. Fakultas Farmasi Universitas Indonesia, Depok 16424, Indonesia

*E-mail:neez_17@yahoo.com

\begin{abstract}
Abstrak
Menstruasi yang menimbulkan nyeri merupakan salah satu masalah ginekologi yang paling umum dialami wanita dari berbagai tingkat usia. Manajemen untuk mengatasi nyeri saat haid diantaranya adalah dengan mengonsumsi obat pereda nyeri haid. Saat ini masyarakat mulai beralih untuk menggunakan tanaman obat sebagai obat alternatif analgesik, diantaranya tanaman jahe merah merah (Zingiber officinale var. Rubrum) dan cengkeh (Syzigium aromaticum). Penelitian ini bertujuan untuk mengetahui pengaruh sediaan krim campuran minyak jahe merah (Zingiber officinale var. Rubrum) dan minyak cengkeh (Syzigium aromaticum) terhadap penurunan intensitas nyeri haid primer. Minyak jahe merah dan minyak cengkeh dibuat menjadi sediaan krim dengan konsentrasi berturut-turut 5\% dan 3\%. Uji stabilitas fisik sediaan krim dilakukan selama 12 minggu. Metode pada uji stabilitas meliputi pengamatan organoleptis (parameternya: pengamatan dan pencatatan $\mathrm{pH}$, Cycling test, dan uji mekanik), dan uji keamanan kepada relawan menggunakan metode uji tempel. Uji manfaat dilakukan pada 30 siswi yang memenuhi kriteria sampel, dilakukan selama 3 jam pada area abdomen bagian bawah. Sediaan krim menunjukkan kestabilan selama 12 minggu dan hasil uji keamanan tidak menimbulkan iritasi sehingga aman digunakan secara topikal. Hasil uji manfaat diukur dengan parameter Visual Analogue Scale, Wong-Baker Faces Pain Rating Scale, frekuensi denyut nadi radialis, frekuensi pernapasan, menunjukkan sediaan krim uji mampu menurunkan intensitas nyeri haid primer. Krim uji memberikan pengaruh penurunan intensitas nyeri yang berbeda nyata dibandingkan krim plasebo, yaitu pada pemakaian krim setelah 3 jam.
\end{abstract}

Kata kunci: nyeri haid primer, Syzigium aromaticum, Zingiber officinale var. Rubrum

\begin{abstract}
Formulation and Benefits of Red Ginger Cream and Clove Oil to Dysmenorrhea. Painful menstruation is one of the most common gynecological problems experienced by women of all ages. To overcome the pain during menstruation is by taking pain medication during menstruation. Nowaday, people are start to use herb as an alternative analgesic medicine, including red ginger plant (Zingiber officinale var.Rubrum) and cloves (Syzigium aromaticum). This research aims to determine the effect of mixture cream between red ginger oil (Zingiber officinale var. Rubrum) and clove oil (Syzigium aromaticum) to reduce the intensity of primary Dysmenorrhea. Oil of red ginger and clove oils are made into cream with a concentration respectively 5\% and 3\%. Physical stability test for creams conducted over 12 weeks and safety testing to volunteers using the patch test. Benefit test carried out for 3 hours at the lower abdominal area. Formulations cream showed stability during 12 weeks and the results of safety test does not cause irritation which make safe to use topically. Benefit test results measured by Visual Analogue Scale parameter, Wong-Baker Faces Pain Rating Scale, the frequency of the radial pulse and respiratory rate, it shows the test cream capable of lowering the intensity of the primary dysmenorrhea. Test creams is able to decrease pain intensity and was significantly different compared to placebo cream where each effect of the cream is observed after 3 hours.
\end{abstract}

Keywords: primary dysmenorrhea, Syzigium aromaticum, Zingiber officinale var. Rubrum

\section{Pendahuluan}

Menstruasi atau haid adalah perdarahan periodik pada uterus yang dimulai sekitar 14 hari setelah ovulasi. Siklus haid merupakan rangkaian peristiwa yang secara kompleks saling memengaruhi dan terjadi secara simultan pada lapisan endometrium, kelenjar hipotalamus dan 
hipofisis, serta ovarium. Usia perempuan, status fisik dan emosi perempuan, obesitas, serta lingkungan memengaruhi pengaturan siklus menstruasi (Hawkins \& Matzuk, 2008). Haid yang menimbulkan nyeri merupakan salah satu masalah ginekologi yang paling umum dialami oleh perempuan dari berbagai tingkat usia (ACOG, 2015; Omidvar, Bakouei, \& Begum, 2016). Nyeri haid dikelompokkan menjadi dua, yaitu nyeri haid primer yang biasa dialami perempuan normal yang menstruasi, dan nyeri haid sekunder yang dialami perempuan penderita tertentu. Nyeri haid primer terjadi, jika tidak ada penyakit atau kelainan organ dalam pelvis. Nyeri haid primer biasanya dimulai dari bulan keenam hingga ke-12 bulan setelah menarche atau pertama kali haid, terjadi pada usia remaja, dan dalam 2-5 tahun setelah pertama kali haid (Omidvar, et al, 2016). Prevalensi nyeri haid bervariasi antara 15,8 hingga 89,5\%, dengan prevalensi tertinggi pada remaja (Kural, Noor, Pandit, Joshi, \& Patil, 2015; Omidvar, et al, 2016).

Obat pereda nyeri haid umumnya mengandung analgesik atau pereda nyeri dan anti prostaglandin seperti aspirin, ibuprofen dan naproksen (Proctor \& Farquhar, 2006). Obat analgesik konvensional yang beredar saat ini, beberapa menimbulkan efek samping. Adanya efek samping ini membuat para perempuan mempertimbangkan terapi yang lain. Masyarakat mulai beralih untuk menggunakan tanaman obat sebagai obat alternatif analgesik karena dianggap lebih aman, minim efek samping, alasan lain juga berkaitan dengan keyakinan, keuangan, dan dan tingkat kesembuhan (Widyatuti, 2008).

Salah satu herbal adalah menggunakan minyak atsiri. Indonesia sebagai negara yang kaya akan berbagai jenis tanaman aromatik, cukup berpotensi dalam produksi dan pengembangan produk minyak, beberapa jenis minyak secara empiris diantaranya diketahui dapat digunakan untuk mengatasi nyeri, seperti minyak jahe merah dan minyak cengkeh (Ozgoli, Torkashvand, Salehi-Moghaddam, Borumandnia, Mojab, \& Minooee, 2016; Samsudin, Kundre, \& Onibala,
2016; Sritoomma, Moyle, Cooke, \& O’Dwyer, 2014).

Kandungan gingerol jahe merah (Zingiber officinale var. Rubrum) lebih tinggi dibanding jahe lainnya (Rehman, et al., 2011). Senyawa identitas pada jahe merah adalah [6]-gingerol dan 3R,5S[6]-gingerdiol. Senyawa [6]-gingerol telah dibuktikan mempunyai aktivitas sebagai antiinflamasi dan analgesik (Kim, et al., 2005). Menurut Lantz (2006) gingerol dan shogaol dapat menghambat produksi/proses pembentukkan prostalglandin, sehingga akan menurunkan kontraksi miometrium. Hasil penelitian oleh Rizk (2013) yang dilakukan pada mahasiswi Fakultas Ilmu Keperawatan Universitas Alexandria di Mesir, bahwa aromaterapi dan pijat abdomen menggunakan minyak jahe menunjukkan pengurangan signifikan pada tingkat keparahan dismenorea primer dan juga minyak jahe dapat meningkatkan perasaan rileks atau tenang. Senyawa eugenol yang terkandung dalam cengkeh mempunyai aktivitas farmakologi sebagai analgesik, antiinflamasi, antimikroba, antiviral, antifungal, antiseptik, antispamosdik antiemetik, stimulan, anastetik lokal sehingga senyawa ini banyak dimanfaatkan dalam industri farmasi (Towaha, 2012). Begitupun dengan salah satu turunan senyawa eugenol, yaitu isoeugenol yang dapat dipergunakan sebagai bahan baku obat antiseptik dan analgesik (Towaha, 2012). Rusaydimanto (2006) menyatakan minyak cengkeh (Syzygium aromaticum) memiliki efek analgesik.

Sediaan uji bentuk krim dipilih karena sediaannya yang mudah merata di kulit (Ansel \& Stockton, 2016). Basis krim yang digunakan dalam penelitian ini adalah jenis vanishing cream. Basis krim dengan jenis vanishing cream lebih banyak disukai pada penggunaan sehari-hari karena memiliki keuntungan yaitu memberikan efek dingin pada kulit tidak berminyak serta memiliki kemampuan penyebaran yang baik (Ugandar \& Deivi, 2013). Pentingnya penelitian ini dilakukan adalah untuk mencari obat alternatif yang efektif dan aman dalam mengatasi nyeri haid primer. 


\section{Metode}

Bahan dasar yang digunakan dalam sediaan krim yaitu Asam Stearat, Setil Alkohol, Propilparaben (Nipasol), Gliseril monostearat (GMS), Butilhidroksitoluen (BHT), Isopropil miristat (IPM), Trietanolamin (TEA), Metilparaben (Nipagin), Propilen glikol, Minyak jahe merah, Minyak cengkeh, dan Akuades. Secara lengkap dapat dilihat pada Tabel 1.

Pengamatan krim uji yang baru dibuat dilakukan berdasarkan beberapa parameter, yaitu pengamatan organoleptis awal, pengukuran $\mathrm{pH}$ awal, dan pengukuran viskositas awal. Uji stabilitas sediaan krim dilakukan dengan metode uji stabilitas dipercepat selama 12 minggu meliputi pengamatan organoleptis, cycling test, uji mekanik. Penelitian ini merupakan penelitian quasi eksperimental dengan menggunakan pre-test-posttest control group design, membandingkan krim uji dan krim plasebo sebagai kontrol.

Responden dalam penelitian ini adalah siswi SMP yang berjumlah 38 orang dengan menggunakan teknik purposive sampling dengan kriteria sampel yaitu yang mengalami nyeri haid hebat dan $>1$ hari serta mengalami takikardi dan takipnea ketika nyeri haid. Sebelum dilaksanakan uji manfaat, terlebih dahulu dilakukan uji iritasi dan uji sensitivitas untuk melihat derajat iritasi dan sensitivitas yang mungkin timbul dalam pelaksanaan. Prosedur pengujian dengan mengoleskan krim pada lengan atas bagian lateral selama 24 jam, lalu diamati adanya reaksi iritasi berupa eritema dan edema sedangkan reaksi sensitivitas berupa timbulnya rasa gatal. Uji manfaat dilakukan kepada 30 siswi yang memenuhi kriteria sampel, dengan cara aplikasi krim:

a. Oleskan krim pada area perut bagian bawah $( \pm 10 \mathrm{~cm}$ di bawah pusar) dengan panjang krim yang dioleskan $\pm 4 \mathrm{~cm}( \pm 0,75 \mathrm{~g})$. Oleskan ketika terasa nyeri haid.

b. Setelah diratakan, kemudian area tersebut dipijat dengan gerakan berputar berkekuatan normal hingga krim terasa meresap ke dalam kulit.

Parameter nyeri haid diamati sebelum dan sesudah diberikan perlakuan dengan durasi pengamatan dalam satu jam, dua jam, dan tiga jam setelah pengolesan, menggunakan skala pengukuran nyeri VAS (Visual Analogue Scale), Wong-Baker Faces Pain Rating Scale, dan pengukuran respon fisiologis nyeri yaitu denyut nadi (takikardia) dan pernapasan (takipnea), data hasil pengukuran nyeri dicatat kemudian data diolah secara statistik.

Tabel 1. Bahan Dasar Krim

\begin{tabular}{lcc}
\hline \multicolumn{1}{c}{ Bahan } & Sediaan Kontrol (\%) & Sediaan Perlakuan (\%) \\
\hline Asam Stearat & 7 & 7 \\
Setil Alkohol & 3 & 3 \\
Propilparaben (Nipasol) & 0,1 & 0,1 \\
Gliseril monostearat (GMS) & 2 & 2 \\
Butilhidroksitoluen (BHT) & 0,1 & 0,1 \\
Isopropil miristat (IPM) & 3 & 3 \\
Trietanolamin (TEA) & 0,1 & 0,1 \\
Metilparaben & 0,1 & 0,1 \\
(Nipagin) & & 15 \\
Propilen glikol & 15 & 5 \\
Minyak jahe merah & - & 3 \\
Minyak cengkeh & - & Hingga 100 \\
Akuades & Hingga 100 & \\
\hline
\end{tabular}

(Sumber: Mitsui, 1997, telah diolah kembali) 


\section{Hasil}

Evaluasi Fisik Sediaan. Pengamatan terhadap organoleptis sediaan krim pada T-0 menunjukkan hasil sebagai berikut:
a. Warna
Krim uji : coklat
Krim plasebo: putih
b. Bau
Krim uji : berbau khas (aromatik)
Krim plasebo: tidak berbau
c. Homogenitas: homogeny

Hasil pengukuran $\mathrm{pH}$ sediaan krim uji pada T-0 menunjukkan nilai 6,50 , sedangkan $\mathrm{pH}$ sediaan krim plasebo pada T-0 menunjukkan nilai 6,40 . Viskositas untuk krim uji pada minggu ke-0 adalah $36.210 \mathrm{cps}$ dan pada minggu ke-12 adalah $27.060 \mathrm{cps}$, Viskositas untuk krim plasebo pada minggu ke-0 adalah 46.780cps dan pada minggu ke-12 adalah $49.660 \mathrm{cps}$. Rheogram yang dihasilkan menunjukkan bahwa sediaan krim uji dan juga krim plasebo memiliki sifat aliran pseudoplastis tiksotropik.

\section{Uji Stabilitas dengan Metode Uji Dipercepat}

a. Uji stabilitas pada suhu $40 \pm 2^{\circ} \mathrm{C}, 4 \pm 2{ }^{\circ} \mathrm{C}, 28$ $\pm 2^{\circ} \mathrm{C}$, Sediaan krim uji dan krim plasebo selama 12 minggu penyimpanan menunjukkan krim plasebo tidak mengalami perubahan warna, krim uji agak mengalami perubahan warna setelah 8 minggu penyimpanan pada suhu tinggi $\left(40 \pm 2^{\circ} \mathrm{C}\right)$ menjadi lebih pekat (coklat tua).

b. Cycling test

Hasil cycling test sediaan krim uji dan krim plasebo menunjukkan bahwa kedua jenis krim memiliki stabilitas yang baik, tidak tampak adanya pemisahan fase dan tidak terlihat adanya kristalisasi. c. Uji mekanik (sentrifugal test) Hasil uji mekanik yang dilakukan pada sediaan krim uji dan krim plasebo menunjukkan tidak terjadinya pemisahan fase setelah dilakukan sentrifugasi pada kecepatan 3800 rpm selama 5 jam terhadap kedua jenis sediaan.

Uji Iritasi dan Uji Sensitivitas. Hasil uji iritasi dan sensitivitas sediaan krim uji dan krim plasebo selama 24 jam pemakaian menunjukkan seluruh relawan tidak mengalami keluhan apapun dan pada pemeriksaan fisik seluruh relawan tidak menunjukkan gejala iritasi dan sensitivitas. Sediaan krim uji dan krim plasebo tidak menyebabkan kulit merah, gatal, perih, ataupun timbul edema sehingga sediaan krim uji dan krim plasebo aman digunakan secara topikal.

\section{Uji Manfaat}

\section{a. Data Demografi}

Gambaran Usia. Gambaran usia tersebut menunjukkan bahwa seluruh relawan termasuk dalam rentang usia remaja. Hal ter-sebut sesuai dengan hasil penelitian Calis, et al. (2009) bahwa prevalensi tertinggi nyeri haid terjadi pada remaja, dan menurut Hediantoro, Hadisaputra, dan Pramayadi (2008) nyeri haid primer biasanya terjadi pada usia remaja (lihat Tabel 2).

Gambaran Usia Pertama Kali Menstruasi. Berdasarkan Tabel 3 menunjukkan dapat diketahui bahwa nyeri haid primer dirasakan relawan pada rentang waktu 1-5 tahun setelah pertama kali menstruasi. Hal tersebut sesuai dengan literatur bahwa nyeri haid primer biasanya dimulai dari bulan ke-6 hingga 12 bulan setelah menarche (Anurogo \& Wulandari, 2011), dan dalam 2-5 tahun setelah pertama kali haid (Hediantoro, et al., 2008).

Tabel 2. Distribusi Frekuensi Relawan Berdasarkan Usia

\begin{tabular}{ccc}
\hline Usia & Frekuensi & Persentase (\%) \\
\hline 13 & 9 & 30 \\
14 & 10 & 33,3 \\
15 & 7 & 23,3 \\
16 & 4 & 13,3 \\
\hline
\end{tabular}


Tabel 3. Distribusi Frekuensi Relawan Berdasarkan Usia Pertama Kali Haid

\begin{tabular}{ccc}
\hline Usia Menarche & Frekuensi & Persentase (\%) \\
\hline 10 & 12 & 40 \\
11 & 8 & 26,7 \\
12 & 7 & 23,3 \\
13 & 3 & 10 \\
\hline
\end{tabular}

Tabel 4. Distribusi Frekuensi Relawan Berdasarkan Kegiatan Olahraga

\begin{tabular}{lcc}
\hline Kegiatan Olahraga & Frekuensi & Persentase \\
\hline Rutin & 13 & 43,3 \\
Tidak rutin & 17 & 56,7 \\
\hline
\end{tabular}

Tabel 5. Hasil Pengukuran Nyeri dengan VAS (Visual Analogue Scale)

\begin{tabular}{cccc}
\hline Waktu & Krim & Std. Deviation & p \\
\hline T-1 & Uji & 1,053 & 1,000 \\
& Plasebo & 1,053 & 1,000 \\
T-2 & Uji & 1,053 & 0,908 \\
& Plasebo & 1,053 & 0,031 \\
T-3 & Uji & 1,031 & 0,000 \\
& Plasebo & 1,073 & \\
T-4 & Uji & 2,977 & 1,033 \\
& Plasebo & & \\
\hline
\end{tabular}

Tabel 6. Hasil Pengukuran Nyeri dengan Wong-Baker Faces Pain Rating Scale

\begin{tabular}{cccc}
\hline Waktu & Krim & Std. Deviation & p \\
\hline $\mathrm{T}-1$ & Uji & 1.070 & 1.000 \\
& Plasebo & 1.070 & 0.930 \\
$\mathrm{~T}-2$ & Uji & 1.040 & 0.930 \\
& Plasebo & 1.070 & 0.000 \\
$\mathrm{~T}-3$ & Uji & 1.040 & 0.070 \\
& Plasebo & 3.030 & \\
$\mathrm{~T}-4$ & Uji & 1.009 & \\
& Plasebo & &
\end{tabular}

Gambaran Kegiatan Olahraga. Berdasarkan data tersebut dapat diketahui bahwa sebagian besar relawan tidak rutin melakukan olah raga, hal tersebut kemungkinan akan berpengaruh terhadap intensitas nyeri haid yang dialaminya. Sesuai dengan hasil penelitian Mahvash, et al. (2012) bahwa aktivitas fisik atau olah raga memiliki dampak positif pada sebagian besar gejala dismenore primer. Olah raga dapat meningkatkan pelepasan hormon endorfin (penghilang nyeri alami) ke dalam aliran darah. Me- lakukan aktivitas fisik atau olah raga secara teratur dapat mengurangi gejala nyeri haid primer.

b. VAS (Visual Analogue Scale) dan WongBaker Faces Pain Rating Scale

Berdasarkan data-data yang diperoleh, menunjukkan bahwa terdapat perbedaan intensitas nyeri haid primer sebelum dan sesudah pemakaian krim uji pada relawan sesuai parameter VAS dan Wong-Baker Faces Pain Rating 
Scale. Tabel 5 dan Tabel 6 menunjukkan bahwa krim uji memiliki perbedaan yang nyata dengan krim plasebo pada pemakaian krim jam ke-3 (T-4) karena nilai $\mathrm{p}<\alpha(0,05)$ yaitu dengan nilai $\mathrm{p}=0,000$. Pada jam ke-1 (T-2) dan ke-2 (T-3) pengaruh penggunaan krim uji terhadap penurunan intensitas nyeri haid primer tidak terlalu berbeda dengan penggunaan krim plasebo karena nilai $\mathrm{p}>0,05$.

c. Frekuensi Denyut Nadi Radialis dan Frekuensi Pernapasan

Berdasarkan data yang diperoleh, menunjukkan terdapat penurunan persentase frekuensi denyut nadi radialis dari takikardia menjadi normal; frekuensi pernapasan dari takipnea menjadi normal; antara sebelum dan sesudah pemakaian krim uji. Pada hasil perhitungan statistik Tabel 7 dan Tabel 8 menunjukkan prevalensi tertinggi nyeri haid terjadi pada remaja. Hasil uji cycling test menunjukkan bahwa sediaan krim uji dan krim plasebo termasuk sediaan krim yang tahan terhadap stress akibat suhu ekstrim. Hasil uji mekanik sediaan krim uji dan krim placebo menunjukkan bahwa kedua jenis krim dapat dianggap memiliki shelf life selama setahun dikarenakan tidak terjadinya pemisahan fase krim pada uji ini. Sediaan krim uji dan krim plasebo aman digunakan secara topikal dan semua calon relawan dapat terus ikut dalam penelitian sebagai relawan karena tidak memperlihatkan tanda iritasi.

Gambaran usia menunjukkan bahwa seluruh relawan termasuk dalam rentang usia remaja. Hal tersebut sesuai dengan hasil penelitian Calis, et al. (2009) bahwa berdasarkan data- data yang diperoleh, menunjukkan bahwa terdapat penurunan persentase frekuensi denyut nadi radialis dari takikardia menjadi normal; frekuensi pernapasan dari takipnea menjadi normal; antara sebelum dan sesudah pemakaian krim uji. Pada hasil perhitungan statistik Tabel 7 dan Tabel 8 menunjukkan bahwa krim uji memiliki perbedaan yang nyata dengan krim plasebo pada pemakaian krim jam ke-3 (T-4) karena nilai $\mathrm{p}<\alpha(0,05)$ yaitu dengan nilai $\mathrm{p}=0,000$. Pada jam ke-1 (T-2) dan ke-2 (T-3) pengaruh penggunaan krim uji terhadap penurunan intensitas nyeri haid primer tidak terlalu berbeda dengan penggunaan krim plasebo karena nilai $\mathrm{p}>0,05$.

\section{Pembahasan}

Tidak adanya sinyal instabilitas pada penyimpanan di tiga suhu yang berbeda selama 12 minggu menunjukkan bahwa produk stabil pada suhu normal $(28 \pm 20 \mathrm{C})$ selama kurang lebih satu tahun (Djajadisastra 2003), dan menurut Hediantoro, dkk (2008) nyeri haid primer biasanya terjadi pada usia remaja. Nyeri haid primer dirasakan relawan pada rentang waktu 1-5 tahun setelah pertama kali menstruasi. Hal tersebut sesuai dengan literatur bahwa nyeri haid primer biasanya dimulai dari bulan ke-6 hingga 12 bulan setelah menarche (ACOG, 2015), dan dalam 2-5 tahun setelah pertama kali haid (Hediantoro, et al., 2008). Sebagian besar relawan tidak rutin melakukan olah raga, sesuai dengan hasil penelitian Mahvash, et al. (2012) bahwa aktivitas fisik atau olah raga memiliki dampak positif pada sebagian besar gejala dismenore primer.

Tabel 7. Hasil Pengukuran Denyut Nadi Radialis

\begin{tabular}{cccc}
\hline Waktu & Krim & Std. Deviation & $\mathrm{p}$ \\
\hline $\mathrm{T}-1$ & Uji & 1,689 & 1,000 \\
& Plasebo & 1,689 & 0,079 \\
$\mathrm{~T}-2$ & Uji & 1,784 & 0,000 \\
& Plasebo & 1,689 & 1,642 \\
$\mathrm{~T}-3$ & Uji & 1,617 & 0,000 \\
& Plasebo & 5,277 & \\
T-4 & Uji & 1,648 & \\
& Plasebo & &
\end{tabular}


Tabel 8. Hasil Pengukuran Frekuensi Pernapasan

\begin{tabular}{cccc}
\hline Waktu & Krim & Std. Deviation & $\mathrm{p}$ \\
\hline $\mathrm{T}-1$ & Uji & 1,971 & 1,000 \\
& Plasebo & 1,971 & 0,752 \\
$\mathrm{~T}-2$ & Uji & 2,087 & 0,248 \\
& Plasebo & 1,971 & 0,407 \\
$\mathrm{~T}-3$ & Uji & 1,906 & 0,000 \\
& Plasebo & 1,999 & \\
$\mathrm{~T}-4$ & Uji & 1,915 & \\
& Plasebo &
\end{tabular}

Penurunan intensitas nyeri haid setelah pemakaian krim uji merupakan efek dari zat aktif yang terkandung dalam sediaan krim uji yaitu gingerol dan eugenol. Gingerol dan eugenol masuk ke dalam sirkulasi darah dan sirkulasi limfatik melalui proses penyerapan kulit. Gingerol yang terkandung dalam minyak jahe merah dan eugenol yang terkandung dalam minyak cengkeh akan menghambat proses pembenktukkan prostaglandin sehingga akan menurunkan kontraksi miometrium dan nyeri haid berkurang, hal tersebut sesuai dengan hasil penelitian Lantz (2006) bahwa gingerol dan shogaol dapat menghambat produksi prostalglandin, serta penelitian Jaafarpour (2015) bahwa eugenol dapat mencegah biosintesis prostaglandin dan mengurangi inflamasi.

Penurunan frekuensi denyut nadi radialis dan frekuensi pernapasan setelah pemakaian krim uji kemungkian adanya efek relaksasi dari minyak atsiri yang terkandung di dalamnya. Hal tersebut sesuai hasil penelitian Rizk (2013) yang dilakukan pada mahasiswi Fakultas Ilmu Keperawatan Universitas Alexandria di Mesir, bahwa aromaterapi dan pijat abdomen menggunakan minyak jahe menunjukkan pengurangan signifikan pada tingkat keparahan nyeri haid primer dan juga minyak jahe dapat meningkatkan perasaan rileks atau tenang. Dalam kondisi rileks, tubuh akan menghentikan produksi hormon adrenalin, sehingga akan menghasilkan reaksi tubuh berupa otot tidak tegang, frekuensi napas dan denyut jantung normal (Kannan, Claydon, Miller, \& Chapple, 2015).
Hasil penelitian ini memperkaya metode pengurang nyeri yang sebelumnya telah digunakan. Dalam konteks promosi kesehatan, perawat dapat memberikan krim tersebut sebagai pendamping metode non-farmakologis lainnya, seperti yoga, relaksasi otot, akupresur, aromaterapi dan metode lainnya (Kannan et al, 2015 \& Soja, Nayak, \& Lobo, 2011). Bagaimanapun, edukasi sangat penting untuk diberikan kepada para remaja puteri menjelang menarke untuk mengubah persepsi tentang nyeri haid (Adinma \& Adinman, 2008).

\section{Kesimpulan}

Sediaan krim campuran minyak atsiri jahe merah dan minyak atsiri cengkeh merupakan sediaan krim yang memiliki performansi yang baik dan aman digunakan secara topikal, memiliki kestabilan fisik yang baik yang terlihat melalui uji mekanik, cycling test, dan pada kondisi penyimpanan dengan suhu berbeda selama 12 minggu.

Krim yang mengandung campuran minyak jahe merah dan minyak cengkeh dapat menurunkan intensitas nyeri haid primer pada siswi SMP. Hal itu terlihat dari terdapatnya perbedaan intensitas nyeri haid yang signifikan $(\mathrm{p}=0,000)$ pada pemakaian krim jam ke-3 antara nyeri haid sebelum dan sesudah pemakaian sediaan krim campuran minyak jahe merah dan minyak cengkeh pada relawan dibandingkan dengan krim plasebo sebagai kontrol (ANS, YA, INR). 


\section{Referensi}

Adinma, E., \& Adinman, J. (2008). Perceptions and practices on menstruation amongst Nigerian secondary school girls. African Journal of Reproductive Health, 12 (1), 74-83.

Ansel, H.C., \& Stockton, S.J.P. (2016). Pharmaceutical calculations (15th Ed.). Philadelphia: LWW.

ACOG. (2015). Dysmenorrhea: Painful periods. Retrieved from: https://www.acog.org/-/media/ For-Patients/faq046.pdf?dmc $=1 \&$ ts $=20180312$ T0414077027

Calis, K.A. (2009). Dysmenorrhea. Available in URL: http://emedicine.medscape.com/article/ 253812-overview.

Djajadisastra, J. (2003). Cosmetic Stability dalam Seminar Setengah Hari HIKI, 18 November 2003, Jakarta.

Hawkins, S.M., \& Matzuk, M.M. (2008). Menstrual cycle: Basic biology. Annals of the New York Academy of Sciences, 1135, 10-18. http://doi. org/10.1196/annals.1429.018

Hediantoro, A., Hadisaputra, W., \& Pramayadi, C.T. (2008). Masalah gangguan haid dan infertilitas. Jakarta: Fakultas Kedokteran Universitas Indonesia.

Jaafarpour, M., Hatefi, M., \& Khajavikhan, J. (2015). Comparative effect of cinnamon and ibuprofen for treatment of primary dysmenorrhea: A randomized double-blind clinical trial. JCDR, 9 (4), 4-7.

Kannan, P., Claydon, L. S., Miller, D., \& Chapple, C. M. (2015). Vigorous exercises in the management of primary dysmenorrhea: A feasibility study. Disability \& Rehabilitation, 37 (15), 1334-1339. doi:10.3109/09638288. 2014.962108 .

Kural, M., Noor, N. N., Pandit, D., Joshi, T., \& Patil, A. (2015). Menstrual characteristics and prevalence of dysmenorrhea in college going girls. Journal of Family Medicine and Primary Care, 4 (3), 426-431. http://doi.org/10.4103/22494863.161345
Lantz, R.C., Chen, G.J., Sarihan, M., Solyom, A.M., Jolad, S.D., \& Timmermann, B.N. (2007). The effect of extracts from ginger rhizome on inflammatory mediator production. Phytomedicine, 14, 123-128.

Mahvash, N., Eidy, A., Mehdi, K., Zahra, M.T., Mani, M., Shahla, H. (2012). The Effect of Physical Activity on Primary Dysmenorrhea of Female University Students. World appl. Sci. J., 17 (10), 1246-1252.

Mitsui, T. (1997). New cosmetic science. Amsterdam: Elsevier.

Omidvar, S., Bakouei, F., Amiri, F. N., \& Begum, K. (2016). Primary dysmenorrhea and menstrual symptoms in Indian female students: Prevalence, impact and management. Global Journal of Health Science, 8 (8), 135-144. http://doi.org/10.5539/gjhs.v8n8p135.

Ozgoli, G., Torkashvand, S., Salehi-Moghaddam, F., Borumandnia, N., Mojab, F., \& Minooee, S. (2016). Comparison of peppermint and clove essential oil aroma on pain intensity and anxiety at first stage of labor. The Iranian Journal of Obstetrics, Gynecology and Infertility, 19 (21), $1-11$.

Proctor, M., \& Farquhar, C. (2006). Diagnosis and management of dysmenorrhoea. British Medical Journal, 332(7550), 1134-1138. doi: 10.1136/bmj.332.7550.1134

Rehman, R., Akram, M., Akhtar, N., Jabeen, Q., Saeed, T., Shah, A.S.M., et al. (2011). Zingiber officinale Roscoe (Pharmacological Activity). J. of Med. Plants Res., 5, 344-348.

Rizk, A.S. (2013). Effect of aromatherapy abdominal massage using peppermint versus ginger oils on primary dysmenorrhea among adolescent girls. J. of American Sci., 9 (11), 597-605.

Rusaydimanto, F. (2006). Efek analgesik ekstrak etanol bunga cengkeh (Caryophylli flos) pada mencit betina Galur Swiss-Webster (Karya Tulis Ilmiah, tidak dipublikasikan). Fakultas Kedokteran, Universitas Kristen Maranatha.

Samsudin, A.R., Kundre, R., \& Onibala, F. (2016). Pengaruh pemberian kompres hangat memakai 
parutan jahe merah (Zingiber Officinale Roscoe Var Rubrum) terhadap penurunan skala nyeri pada penderita gout artritis di Desa Tateli Dua Kecamatan Mandolang Kabupaten Minahasa. eJurnal Keperawatan, 4 (1). Diperoleh dari https://ejournal.unsrat.ac.id/index.php/jkp/artic le/viewFile/12128/11709.

Soja, S., Nayak, B.S., \& Lobo, D.J. (2011). A Study to evaluate the effectiveness of acupressure on menstrual discomforts among adolescent girls. International Journal of Nursing Education, 3 (2), 107-110.

Sritoomma, N., Moyle, W., Cooke, M., \& O’Dwyer, S. (2014). The effectiveness of Swedish massage with aromatic ginger oil in treating chronic low back pain in older adults: A randomized controlled trial. Complementary Therapies in Medicine, 22 (1), 26-33.

Towaha, J. (2012). Manfaat Eugenol Cengkeh dalam Berbagai Industri di Indonesia. Perspektif, 11 (2), 79-90.

Ugandar, R.E., \& K. Deivi, K.S. (2013). Formulation and evaluation of natural palm oil-based vanishing cream. International Journal of Pharmaceutical Sciences and Research, 4 (9), 3375-3380. http://dx.doi.org/10.13040/IJPSR. 0975-8232.4(9).3375-80

Widyatuti, W. (2008). Terapi komplementer dalam keperawatan. Jurnal Keperawatan Indonesia, 12(1), 53-57. doi:http://dx.doi.org/10.7454/jki. v12i1.200. 